\title{
Modulatory effects of positive mood and approach motivation on reward processing: Two sides of the same coin?
}

\author{
Katharina Paul $^{1}$ (D) Gilles Pourtois $^{1} \cdot$ Eddie Harmon-Jones $^{2}$
}

Published online: 10 February 2020

(C) The Psychonomic Society, Inc. 2020

\begin{abstract}
In a previous study (Paul \& Pourtois, 2017), we found that positive mood substantially influenced the neural processing of reward, mostly by altering expectations and creating an optimistic bias. Under positive mood, the Reward Positivity (RewP) component and fronto-medial theta activity $(\mathrm{FM} \theta)$ in response to monetary feedback were both changed compared with neutral mood. Nevertheless, whether positive valence per se or motivational intensity drove these neurophysiological effects remained unclear. To address this question, we combined a mindset manipulation with an imagery procedure to create and maintain three different affective states using a between-subjects design: a neutral mood, and positive mood with either high or low motivational intensity. After mood induction, 161 participants performed a simple gambling task while 64-channel EEG was recorded. FM $\theta$ activity results showed that irrespective of motivational intensity, positive compared with neutral mood altered reward expectancy. By comparison, RewP was not affected by positive mood nor motivational intensity. These results suggest that positive mood, rather than motivational intensity, is likely driving the change in reward expectation during gambling, which could reflect the presence of an optimistic bias. Moreover, at the methodological level, they confirm that the RewP ERP component and FM $\theta$ activity can capture dissociable effects during reward processing.
\end{abstract}

Keywords Mood · Motivation · Erp · Reward

Reward processing is a cardinal component of reinforcement learning. More specifically, predictions about future successes are initially formed, and subsequent deviations between the actual outcome and its prediction are swiftly detected with the goal to adjust behaviour accordingly (Fiorillo, Tobler, \& Schultz, 2003; Holroyd \& Coles, 2002; Sutton \& Barto, 1998). However, this fundamental process is not encapsulated but liable to changes in the environment, including the motivational and affective state of the participant (Nusslock \& Alloy, 2017; Umemoto \& Holroyd, 2017). In agreement with this view, in a recent electroencephalography (EEG) study

Electronic supplementary material The online version of this article (https://doi.org/10.3758/s13415-019-00764-6) contains supplementary material, which is available to authorized users.

Katharina Paul

katharina.paul@ugent.be

1 Department of Experimental, Clinical, and Health Psychology, Ghent University, Ghent, Belgium

2 School of Psychology, The University of New South Wales, Sydney, Australia
(Paul \& Pourtois, 2017), we found that under positive mood, reward sensitivity, and expectancy during gambling were increased compared with neutral mood.

Although these first neurophysiological results were intriguing and lent support to the notion of a moodcongruency effect during reward processing (Eldar, Rutledge, Dolan, \& Niv, 2016; Loewenstein \& Lerner, 2003), an important unanswered question remained. More specifically, whether positive mood per se, or alternatively (approach) motivational intensity drove these effects, remained unclear. Positive mood is a heterogeneous construct, subsuming states ranging from contentment to amusement, which all have different adaptive functions that could presumably lead to different effects on reward processing (Shiota et al., 2014). Moreover, a key nonorthogonal dimension of positive mood is motivational intensity, particularly of approach motivation. Approach motivational intensity has been defined as the strength of the urge to go towards incentives, events, or situations (Harmon-Jones, Harmon-Jones, \& Price, 2013b). In this framework, positive emotions, such as desire and determination, are associated with high approach motivational intensity (or pre-goal positive affect), whereas satisfaction and amusement are associated with low approach 
motivational intensity (or post-goal positive affect). Earlier studies found that high and low approach motivated positive affect had different effects on information processing, including the narrowing- broadening effect of visuo-spatial attention (for a review, see Gable \& Harmon-Jones, 2010; HarmonJones, Gable, \& Price, 2013a). Because positive affect and approach motivation often are confounded (in nature and in experiments), it was therefore unsettled based on our previous study (Paul \& Pourtois, 2017) whether positive mood per se, or instead approach motivation, actually drove the modulation of reward processing seen at the EEG level.

Reward processing has been studied extensively in the past using EEG, and in particular, the event-related brain potentials (ERPs) method. The most frequently studied ERP component is the Reward-Positivity (RewP), peaking at fronto-central electrodes around $250 \mathrm{~ms}$ after evaluative feedback onset. The RewP is typically larger for positive compared to negative and better than expected outcomes (Gheza, Paul, \& Pourtois, 2018b; Holroyd, Pakzad-Vaezi, \& Krigolson, 2008; Proudfit, 2015). Given its neurophysiological characteristics, the RewP has been proposed as a valid marker of reward processing (Bress \& Hajcak, 2013; Proudfit, 2015; Umemoto \& Holroyd, 2017). Although informative, the ERP method has some inherent limitations (e.g., it is based on a standard averaging technique) and is blind to other neurophysiological effects, which can be revealed using an appropriate timefrequency decomposition of the EEG signal (Fell et al., 2004; Makeig et al., 2002). Among them, fronto-medial theta activity $(4-8 \mathrm{~Hz}, \mathrm{FM} \theta)$ has been put forward recently as a valid neurophysiological marker of the need for cognitive control (Cavanagh, Figueroa, Cohen, \& Frank, 2012a; Hajihosseini \& Holroyd, 2013; Hauser et al., 2014; MasHerrero \& Marco-Pallarés, 2014). FM $\theta$ activity increases for response errors, conflicts, novel stimuli, and importantly for outcomes that turned out to be worse or better than expected, i.e. when reward is expected but omitted, or conversely, when reward is not predicted but well delivered (Gheza, De Raedt, Baeken, \& Pourtois, 2018a; Paul \& Pourtois, 2017).

Capitalizing on these complementing electrophysiological correlates of reward processing, we found in our previous EEG study (Paul \& Pourtois, 2017) that positive mood was accompanied by a blunted FM $\theta$ activity for reward feedback, when this reward was unexpected. Whereas participants in the neutral mood showed a larger FM $\theta$ response for unexpected compared with expected outcomes (irrespective of their valence), participants in positive mood showed this effect for the no-reward feedback only, as if these participants treated unexpected reward as expected (Mayer, Gaschke, Braverman, \& Evans, 1992; Sharot, Korn, \& Dolan, 2011; Wright \& Bower, 1992). Additionally, positive mood was accompanied by an increased RewP, which was in line with previous EEG studies showing an increased RewP for traits associated with positive affect, including extraversion (Cooper, Duke, Pickering, \&
Smillie, 2014; Smillie, Cooper, \& Pickering, 2011) and reward sensitivity (Bress \& Hajcak, 2013; Cooper et al., 2014; Umemoto \& Holroyd, 2017).

However, other EEG studies have linked increases in the amplitude of the RewP with approach motivation, rather than (positive) mood. For example, Angus, Kemkes, Schutter, and Harmon-Jones (2015) reported an increased RewP after the induction of anger, which is corresponding to a negative affective state characterized by enhanced approach motivation (Carver \& Harmon-Jones, 2009; E. Harmon-Jones, 2007; E. Harmon-Jones, Harmon-Jones, Abramson, \& Peterson, 2009). These authors suggested that the RewP component is not modulated by affective valence, but rather motivational direction/intensity. Conceptually similar research has revealed that trait anger also relates to an increased RewP (Tsypes, Angus, Martin, Kemkes, \& Harmon-Jones, 2019). The idea that approach motivation influences RewP is also supported by other EEG studies, showing an increased RewP in trials where approach motivation was induced by the prospect of getting monetary reward in these trials (Threadgill \& Gable, 2016, 2018) or increasing reward magnitude (Paul et al., in press). Accordingly, it seems plausible to assume that approach motivation rather than positive mood might have caused the change in the RewP, as well as FM $\theta$, seen in our previous EEG study (Paul \& Pourtois, 2017).

To test this hypothesis, we devised a between-subjects design suited to disentangle effects of approach motivation from positive mood on reward processing. Using previously validated scripts and an imagery procedure (E. Harmon-Jones, Harmon-Jones, Fearn, Sigelman, \& Johnson, 2008; Paul, Vassena, Severo, \& Pourtois, 2019; Vanlessen, Rossi, De Raedt, \& Pourtois, 2013), either a neutral mood, positive mood with low approach motivation, or positive mood with high approach motivation was induced. This was combined with a gambling task (Moser, Hajcak, \& Simons, 2005) to extract the RewP and FM $\theta$ activity at the feedback level. Subjective reports (see Paul \& Pourtois, 2017), as well as frontal alpha-asymmetry (Coan \& Allen, 2004; E. HarmonJones \& Gable, 2018; Smith, Reznik, Stewart, \& Allen, 2016) served as main manipulation checks to corroborate the presence of differential affective states elicited in these three groups. We compared two hypotheses. If positive mood accounted for the changes in reward processing seen previously at the EEG level (Paul \& Pourtois, 2017), then we surmised that a larger RewP and blunted FM $\theta$ activity for unexpected reward should be observed for both conditions with positive mood (regardless of motivational intensity) compared to neutral mood in the current study. In comparison, if approach motivation mostly explained these changes, then we expected that a larger RewP and blunted FM $\theta$ activity for unexpected reward should be most visible for the high compared to the low approach motivation condition, without any similar effect seen in the neutral mood group. 


\section{Methods}

\section{Participants}

Sample size was based on our previous results (Paul \& Pourtois, 2017), where we found a large effect of positive mood on FM $\theta\left(\eta p^{2}=0.16,90 \%\right.$ confidence interval [CI] [0.06-0.27]) and a sensitivity analysis performed in $\mathrm{G}^{*}$ power (Faul, Erdfelder, Lang, \& Buchner, 2007). In order to detect a medium sized effect $\left(\eta p^{2}=0.06\right.$, i.e., the lower bound of the previous effect size), with a power (1- $\beta$ ) of 0.80 , the current betweensubjects design required a sample of 159 subjects. Data collection was carried out at two locations but with the same experimental setup and main researcher. ${ }^{1}$

Ninety-nine students of The University of New South Wales (UNSW) were compensated with course credits and received an AU $\$ 15$ "bonus." This part of the study was approved by the UNSW Human Research Ethics Advisory Panel C: Psychology. Seventy-four participants were tested at Ghent University and compensated with $€ 20$ and a bonus of $€ 10$. This part of the study was approved by the ethical committee of the Faculty of Psychology and Educational Sciences at Ghent University. All participants were right handed, provided written informed consent before the start of the experiment, and were randomly assigned to one of three mood conditions.

One participant did not complete the experiment, because she felt nauseous; one participant had to be excluded due to technical problems during data acquisition or noisy data; and four other participants had to be excluded due to poor performance (i.e., less than $60 \%$ correct responses, see catch trials below). Additionally, six participants were excluded, because their happiness or desire ratings deviated more than $2.5 \mathrm{SD}$ from the group mean. Following these exclusions, 54 participants were included in the neutral mood condition, 54 participants in the low approach positive mood condition, and 53 in the high approach positive mood condition. The three groups were balanced for age and gender $(M N$ eutral $=21.46$ years, standard deviation $[S D]=3.61,34$ females, $M$ Low approach positive $=21.63$ years, $S D=3.62,34$ females, $M$ High approach positive $=22.49$ years, $S D=4.74,27$ females). ${ }^{2}$

\section{Mood Induction Procedure}

To change the mood state of the participants, we used a between-subjects design and combined two previously validated experimental procedures. A mindset manipulation (E. Harmon-Jones et al., 2008) was combined with an imagery

\footnotetext{
${ }^{1}$ A table with the descriptive statistics of these two groups of participants can be found in the supplementary material, see Supplementary Table 1.

2 There was no significant difference in gender distribution between the three groups, $\chi^{2}(3)=2.12, p=0.35$.
}

procedure (Bakic, Jepma, De Raedt, \& Pourtois, 2014; Paul \& Pourtois, 2017; Vanlessen et al., 2013). Furthermore, affect congruent music was played during the mood induction procedure and the rest of the experiment. The music pieces were selected from an online data base (https://www.melodyloops. com/). More specifically "the numbers" was played for the neutral mood, the "autumn song" was used for the low approah positive mood and the "world of heroic adventures" for the high approach positive mood. During the mindsetmanipulation, participants had to choose an appropriate personal experience and to describe (by typing) the situation for 5 minutes. They were encouraged to describe the situation in as many details as possible. In the neutral mood condition, participants were instructed to describe an ordinary day in their life, in which no positive or negative event occurred. In the low approach positive mood condition, participants were instructed to recall a situation that made them feel very good about themselves. Instructions emphasized that it should be an event that happened to them and did not result from something that they did. In comparison, in the high approach positive mood condition, participants were instructed to describe an intended project that they would accomplish someday and that they had already started to work on. They were told to describe the main steps involved in this project and the feelings of achievement. These specific instructions have been used previously and found to be efficient to alter approach motivation (E. Harmon-Jones et al., 2008). Afterwards, during the imagery procedure, they were asked to close their eyes for 3 minutes and try to imagine themselves as vividly as possible in the situation that they just described.

Before the actual mood induction, the experimenter first trained all participants in multisensory imagery from their own perspective with a standard four-step exercise involving a lemon (Holmes, Coughtrey, \& Connor, 2008; Holmes, Mathews, Dalgleish, \& Mackintosh, 2006). More specifically, participants were asked to imagine that they were 1) holding a lemon, 2) cutting it, 3) having a close look and smelling it, and 4) feeling a drop of the lemon juice in an eye. After this practice session, and independently of the experimenter, instructions were presented on the computer monitor. During this phase, the experimenter was not present and was therefore blind to the specific mood condition assigned.

In order to maintain the effect of the mood induction throughout the experimental session, shorter repetitions of this mood induction were introduced twice, besides the use of a specific music excerpt played in the background (see above). These repetitions used the same instructions as the main mood induction procedure provided at the beginning of the experiment. Again, participants were asked to continue with their detailed description and to close their eyes (only for $90 \mathrm{sec}-$ onds) to imagine themselves in the situation. 


\section{Manipulation Checks}

Subjective Ratings We used subjective ratings provided at baseline and immediately after the mood induction to assess its effectivity. Six subscales of the Discrete Emotions Questionnaire (DEQ) (C. Harmon-Jones, Bastian, \& Harmon-Jones, 2016), namely happiness, desire, relaxation, anger, anxiety, and sadness, were used. Each of these subscales consisted of four items answered on a seven-point scale. Additional items asking about arousal and determination also were included. The order of the items was alternated across participants and each measurement point.

Frontal Alpha-Asymmetry During the initial EEG resting state period (3 minutes), as well as during the imagery within the subsequent mood induction sessions (lasting 3 minutes/90 seconds each), alpha power at predefined frontal sites was extracted and analyzed. After preprocessing (see hereafter), recordings were manually inspected to remove segments containing artefacts before overlapping epochs were generated (length 2 seconds, overlap 1 second). On average, 299 ( $S D=62.8)$ epochs were included for the longer recordings at the beginning of the experiment and $159(S D=19.9)$ for the shorter recordings corresponding to repetitions of the mood induction. We computed the power spectral density by applying a fast Fourier transform on the task data (spectopo function), obtaining a $\mathrm{dB}$ converted estimation of relative power in a range of frequencies. Alpha power was defined as the average in the $8-13 \mathrm{~Hz}$ range. Asymmetry (difference) scores were computed as the natural log right - natural $\log$ left alpha power at F8/F7. Alpha power is inversely related to cortical activity (Cook, O'Hara, Uijtdehaage, Mandelkern, \& Leuchter, 1998). Greater left frontal activity (hence, lower left alpha power) is associated with approach motivation, whereas greater right frontal activity is associated with avoidance motivation (Coan \& Allen,
2004; E. Harmon-Jones \& Gable, 2018). Therefore, higher scores on this asymmetry score indicate greater left relative to right hemispheric activity and thus higher approach motivation.

\section{Task}

A variant of a previously validated gambling task was used (Hajcak, Moser, Holroyd, \& Simons, 2007; Paul \& Pourtois, 2017; Figure 1). On each trial, participants chose one of three doors by pressing with their right index finger a corresponding key on the keyboard. After a fixation dot $(800 \mathrm{~ms})$, this choice was followed by either reward feedback (green "+"), indicating a reward of $\$ 0.14 / € 0.10$, or no-reward feedback (red "o"; $1000 \mathrm{~ms}$ ). At the beginning of each trial, participants were informed about reward probability with a visual cue $(1,000$ $\mathrm{ms})$. The cue was presented in the form of a small circle filled to one or two thirds (black/white), indicating a reward probability of $33 \%$ or $66 \%$. Feedback was only related to these objective reward probabilities and not the choices of the participants. All participants ended up with a preset winning of $\$ 15 / € 10$.

To ensure that participants paid attention to the cue informing about reward probability as well as the feedback, additional questions were occasionally asked and used as catch trials. On some trials $(n=38)$, they were asked about the current reward probability just after they saw the visual cue ("How many doors do contain a prize?"), and they responded by pressing a number on the keyboard (either 1 or 2). On 38 different trials, they were asked how much they actually expected to receive this specific feedback, just after having received it, and they responded on a visual analog scale (anchored with "not at all" and "a lot"). On 12 other trials, they were asked both questions. All stimuli were shown against a grey background on a 23 -inch LCD screen and the experiment was controlled using E-Prime Professional (V 2.0.10, Psychology Software Tools Inc., Sharpsburg, PA).

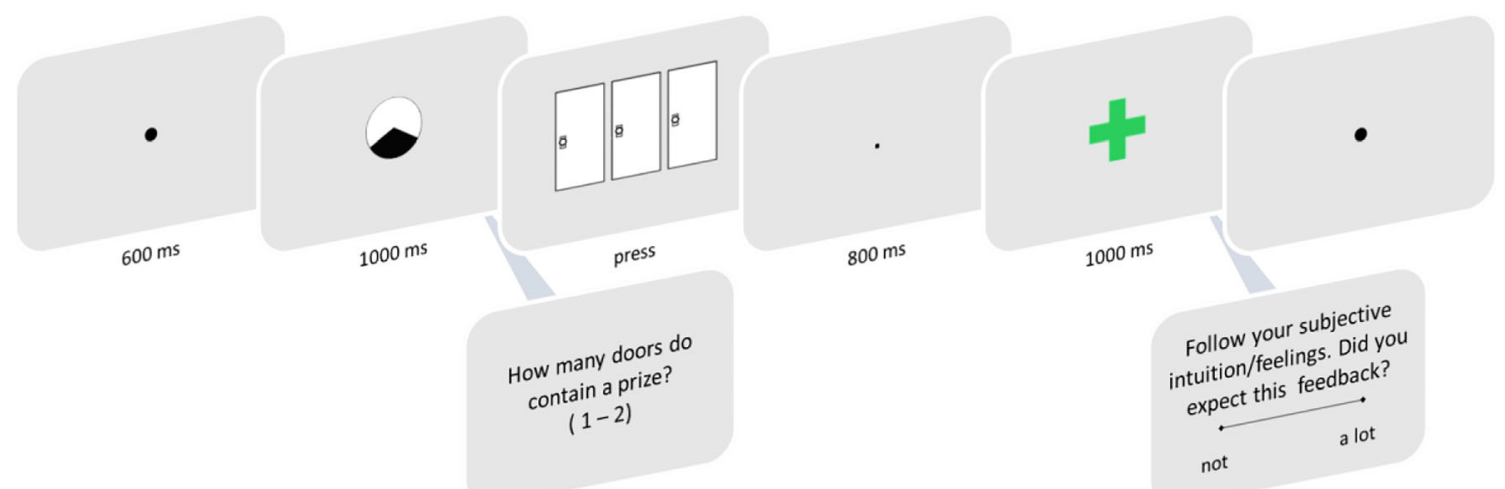

Fig. 1 Overview of the trial structure. At the beginning of each trial, participants were informed about reward probability using a specific cue $(33 \%$ or $66 \%)$. After they chose one door, they received either

monetary reward or no-reward feedback. Additionally, in some trials, participants had to report the current reward probability after the visual cue was shown and/or rate feedback expectations after receiving it. 


\section{General Procedure}

Participants started with instructions and six practice trials, before they rated their current affective state using the DEQ (C. Harmon-Jones, Bastian, \& Harmon-Jones, 2016) and an EEG resting state with closed eyes was recorded for 3 minutes. These first measurements served as baseline mood ratings. Afterwards, participants practiced their visual imagery abilities with the lemon exercise (Holmes et al., 2008) before they completed the mood induction procedure. The DEQ was administered again before participants continued with the gambling task. The task consisted of 210 trials in total (105 of small reward probability) and was presented in 3 blocks of 70 trials each. After each block, participants had a short break. During this break, they were informed about their current pay-off, before a shorter version of the mood induction was applied and the DEQ was repeated. At the end of the experiment, participants filled in the English version of the BIS/BAS scales (Carver \& White, 1994) and a life satisfaction questionnaire (Diener, Emmons, Larsen, \& Griffin, 1985). Participants at Ghent University, also had to answer some additional questions regarding the feedback.

\section{Recording and Preprocessing of Electrophysiological Data}

EEG was recorded using 64 electrodes positioned according to the 10-10 EEG system. Additional electrodes were placed on the mastoids and to measure eye movements, above and below the left eye (vertical eye movements) and the two canthi (horizontal eye movements). Signals were recorded using a BioSemi Active Two System (BioSemi, Amsterdam,

Table 1 Means (Standard Deviations) of EEG components and expectedness ratings

\begin{tabular}{|c|c|c|c|c|}
\hline Mood & $\begin{array}{l}\text { Expected } \\
\text { No-Reward } \\
\end{array}$ & $\begin{array}{l}\text { Unexpected } \\
\text { No-Reward } \\
\end{array}$ & $\begin{array}{l}\text { Expected } \\
\text { Reward }\end{array}$ & $\begin{array}{l}\text { Unexpected } \\
\text { Reward }\end{array}$ \\
\hline \multicolumn{5}{|l|}{ FM $\theta$ activity } \\
\hline Neutral & $2.65 \quad(2.03)$ & $3.03 \quad(1.75)$ & $1.71 \quad(1.71)$ & $2.17 \quad(1.38)$ \\
\hline Low approach & $2.96 \quad(1.70)$ & $3.51 \quad(1.63)$ & $2.42 \quad(1.68)$ & $2.56 \quad(1.80)$ \\
\hline High approach & $2.51 \quad(1.21)$ & 3.09 (1.43) & $2.07 \quad(1.46)$ & $1.89(1.23)$ \\
\hline \multicolumn{5}{|l|}{$\operatorname{RewP}$} \\
\hline Neutral & $1.71 \quad(5.66)$ & $1.45(6.53)$ & $6.86 \quad(7.60)$ & $8.61 \quad(6.75)$ \\
\hline Low approach & $1.00 \quad(7.37)$ & $1.91 \quad(6.98)$ & $6.42 \quad(7.50)$ & $6.79 \quad(8.30)$ \\
\hline High approach & $2.36 \quad(5.13)$ & $3.00 \quad(5.44)$ & $7.75 \quad(6.58)$ & $8.50 \quad(7.01)$ \\
\hline \multicolumn{5}{|c|}{ Expectedness } \\
\hline Neutral & $52.5(10.9)$ & $43.0(10.6)$ & $59.5(9.51)$ & $52.9(13.2)$ \\
\hline Low approach & $50.0 \quad(17.1)$ & $40.3(16.3)$ & 61.9 (14.9) & $52.6 \quad(16.7)$ \\
\hline High approach & $54.7(15.2)$ & $38.2(13.5)$ & $63.3(12.3)$ & $46.9 \quad(16.1)$ \\
\hline
\end{tabular}

The Netherlands) with ActiView software (version 7.06, BioSemi). EEG was sampled at $512 \mathrm{~Hz}$ and referenced online to the common mode sense (CMS) and passive driven right leg (DRL) electrodes. The EEG was preprocessed offline with EEGLAB 13.5.4b (Delorme \& Makeig, 2004), implemented in Matlab R2013b, and included a $0.03 / 35 \mathrm{~Hz}$ high/low pass filter and re-referencing to the mastoids. For data cleaning, the Algorithmic Pre-Processing Line for EEG (APPLE, Cavanagh et al., 2017) was applied, which combines functions from the open source toolboxes FASTER (Nolan, Whelan, \& Reilly, 2010) and EEGLAB with custom algorithms for automatically identifying the most likely independent component associated with eye blinks, interpolating bad channels, and removing bad epochs. The codes used for EEG data preprocessing can be found on https://osf.io/kc42t/. For identifying bad channels, EEGLAB and Faster marked activity exceeding a probability of $2.5 \mathrm{SD} / \mathrm{z}$-scores (with a maximum of 5 electrodes). On average $3.89(S D=0.84)$ ICA components were removed and $4.10(S D=1.76)$ channels interpolated.

Feedback-related epochs were extracted from $-1,000$ to 2,700 ms centered around the feedback onset, and baseline corrected using the -250 to $0 \mathrm{~ms}$ interval before it. For each subject separately, the EEG data corresponding to the four main experimental conditions were extracted: expected and unexpected feedback, corresponding to a probability of $1 / 2=33 \%$ and $2 / 3$ $=67 \%$, respectively, separately for reward and no-reward feedback. On average, $5.75 \%(S D=3.01)$ of epochs were rejected using the FASTER algorithms that detect epochs deviating $2.5 \mathrm{z}-$ scores from the mean data, variance, and maximum amplitude. To account for different signal-to-noise ratios between conditions, a subset of trials of the more frequent expected conditions $(M=65.1, S D=2.23$, range $=55-69)$ was selected and used to match the smaller trial number available for the unexpected conditions $(M=33.5, S D=0.73$, range $=31-35)$. This selection was performed randomly for each individual subject.

The RewP was quantified at $\mathrm{Fz}$ as the mean amplitude between 230 and $280 \mathrm{~ms}$ post feedback onset. This time window and electrode location were selected based on the maximum of the difference between no-reward and reward feedback across all conditions (i.e., $255 \mathrm{~ms}$ ) and was identical to our previous studies (Gheza, Paul, et al., 2018b; Paul \& Pourtois, 2017; Paul et al., 2019). The time frequency analysis was done using EEGLAB built-in std ersps function (2.4-21 cycles, $0.8-35 \mathrm{~Hz}, 180 \mathrm{log}$-spaced frequencies, 300 time points per epoch). The -500 to $-200 \mathrm{~ms}$ time interval before feedback onset was used for baseline correction. FM $\theta$ activity (4-8 Hz) was defined as the mean within 200-400 ms at Fz. This electrode position was chosen based on the local maximum of the difference between no-reward and reward feedback for the mean voltage or mean power values obtained (Figures 4E and 5B), and previous EEG studies using the same experimental procedure (Gheza, Paul, et al., 2018b; Paul \& Pourtois, 2017). 


\section{Data Analysis}

For all analyses, the significance alpha cutoff was set to 0.05 (two-tailed). Data analysis was performed in JASP (0.8.2., Jasp Team 2017) and post-hoc analyses were computed using SPSS (22, IBM statistics). Greenhouse-Geisser correction was performed when sphericity was violated. Moreover, Bayesian statistics for the ANOVA were used with the recommended standard settings and priors. Materials, data and analysis scripts are publicly available on the Open Science Framework (https://osf.io/kc42t/).

Manipulation Checks A mixed model ANOVA with Mood (three groups: neutral, low approach positive, and high approach positive) as between-subjects factor and Time (4 assessments: baseline and 3 manipulations) as within-subject factor was used, separately for each scale and the frontal alpha-asymmetry index. All post-hoc comparisons can be found in the Supplementary material.

Catch Trials For reward probability (cue), accuracy data were computed. The raw data were first transformed into percentages of correct responses and compared between groups by means of a one-way ANOVA. For the feedback, expectedness ratings were first transformed into percentage, arbitrarily setting one anchor to 0 and the other one to 100 . These accuracy data were analyzed using separate mixed-model ANOVAs with the within-subject factors feedback Valence (reward or no-reward) and feedback Expectancy (expected or unexpected), and the between-subjects factor Mood (neutral, low approach positive, or high approach positive).

EEG data The amplitude of the RewP and FM $\theta$ activity were analyzed using separate mied- model ANOVAs with the within-subject factors feedback Valence (reward or noreward) and feedback Expectancy (expected or unexpected), and the between-subjects factor Mood (neutral, low approach positive, high approach positive).

\section{Results}

\section{Manipulation Checks}

Subjective Ratings. The ANOVA run on the data for the happiness subscale of the DEQ showed significant effects of Time, $F(2.6,408)=7.83, p<0.001, \eta^{2}=$ 0.043 , Mood, $F(2,158)=7.54, p=0.001, \eta^{2}=0.087$, and the interaction between them, $F(5.2,408)=8.31, p$ $<0.001, \eta^{2}=0.091$. While the three mood conditions did not differ from each other at the baseline measurement ( $p s \geq 0.99$ ), participants in low approach positive mood reported more happiness for all successive assessments compared with participants in neutral $\operatorname{mood}(p s \leq$
0.001). The high approach positive mood group reported only marginally significant higher levels of happiness compared to the neutral group ( $p \mathrm{~s}=0.055-0.095)$. The high approach positive mood group had slightly higher levels of happiness compared with the low approach positive mood condition ( $p s=0.043-0.11$; Figure 2).

The data for the relaxation subscale showed significant main effects of Time, $F(2.6,407)=4.86, p=0.002, \eta^{2}=$ 0.027 , and Mood, $F(2,158)=9.09, p<0.001, \eta^{2}=0.10$, as well as a significant interaction between them, $F(5.1,407)=$ $8.91, p<0.001, \eta^{2}=0.10$. Compared with the baseline measurement, relaxation did not change over time for the neutral mood group (all $p$ s $>0.99$ ). However, participants in high approach positive mood reported feeling less relaxed after the first mood induction as well as all subsequent assessments (all $p$ s $\leq 0.001$ ). Participants in the low approach positive mood reported slightly increased feelings of relaxation after the first mood induction compared with the baseline ( $p=$ 0.014 ), but no other changes were significant ( $p \mathrm{~s} \geq 0.15$ ).

The ANOVA run on the data for the desire subscale of the DEQ showed a significant interaction between Time and Mood, $F(5,397)=2.39, p=0.037, \eta^{2}=0.029$. Participants in the high approach positive mood reported (trendsignificant) higher levels of desire compared with the neutral group after the first and second mood inductions $(p=0.032$ and 0.055$)$, whereas there was no difference between the groups for any other time point ( $p \mathrm{~s} \geq 0.28$ ). No other main effect was significant $F_{\mathrm{S}} \leq 2.03, p \geq 0.13, \eta^{2} \leq 0.025$.

The ANOVA run on the data for the anxiety subscale of the DEQ revealed a significant effect of Time, $F(2.3,358)=$ $15.31, p<0.001, \eta^{2}=0.084$, Mood, $F(2,158)=3.74, p=$ $0.026, \eta^{2}=0.045$, and a significant interaction between Time and Mood, $F(4.5,358)=4.99, p<0.001, \eta^{2}=0.055$. Compared with the baseline measurement, anxiety did not change over the course of the experiment for neutral and high approach positive moods (all $p \mathrm{~s} \geq 0.049$ ). However, participants in low approach positive mood reported feeling less anxious after the first mood induction as well as all repetitions (all $p \mathrm{~s} \leq 0.001$ ). For the sadness and anger subscales, no significant main or interaction effects were found, $F \mathrm{~s} \leq 2.06, p \mathrm{~s} \geq$ $0.11, \eta^{2} \leq 0.039$.

The ANOVA run on the data for the determination item showed a significant effect of Time, $F(2.8,443)=$ $6.54, p<0.001, \eta^{2}=0.036$, Mood, $F(2,149)=8.53, p$ $<0.001, \eta^{2}=0.11$, as well as a significant interaction between Time and Mood, $F(5.5,443)=6.39, p<0.001$, $\eta^{2}=0.076$. While determination did not differ between the three moods at baseline ( $p s \geq 0.99)$, participants in high approach positive mood reported feeling more determined for all successive time points compared with the neutral and low approach moods $(p \mathrm{~s}=0.074-0.001)$. The ANOVA run on the arousal ratings did not show any significant effect, $F_{\mathrm{s}} \leq 1.60, p \mathrm{~s} \geq 0.16, \eta^{2} \mathrm{~s} \leq 0.021$. 


\section{Manipulation Checks}
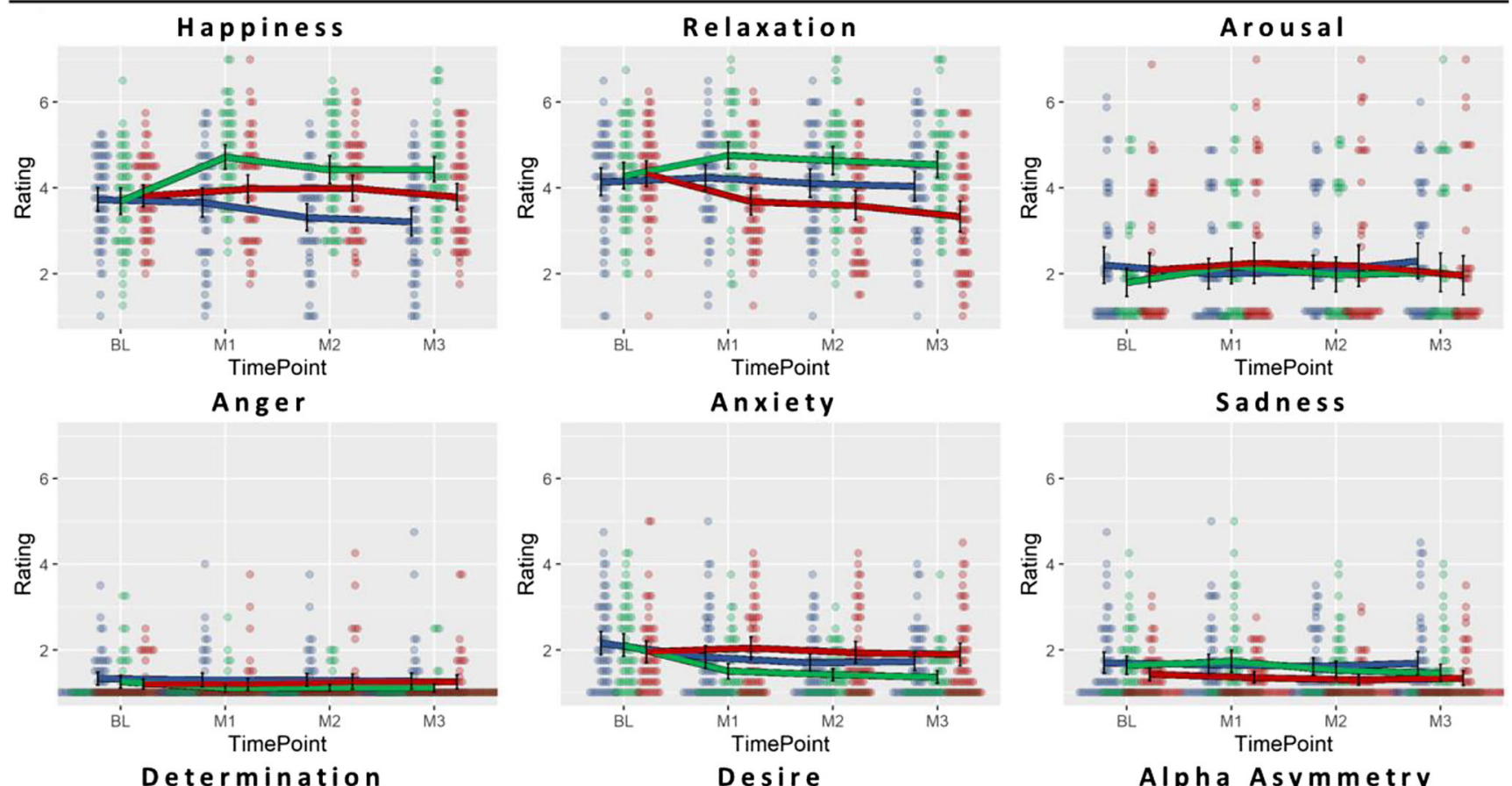

Determination
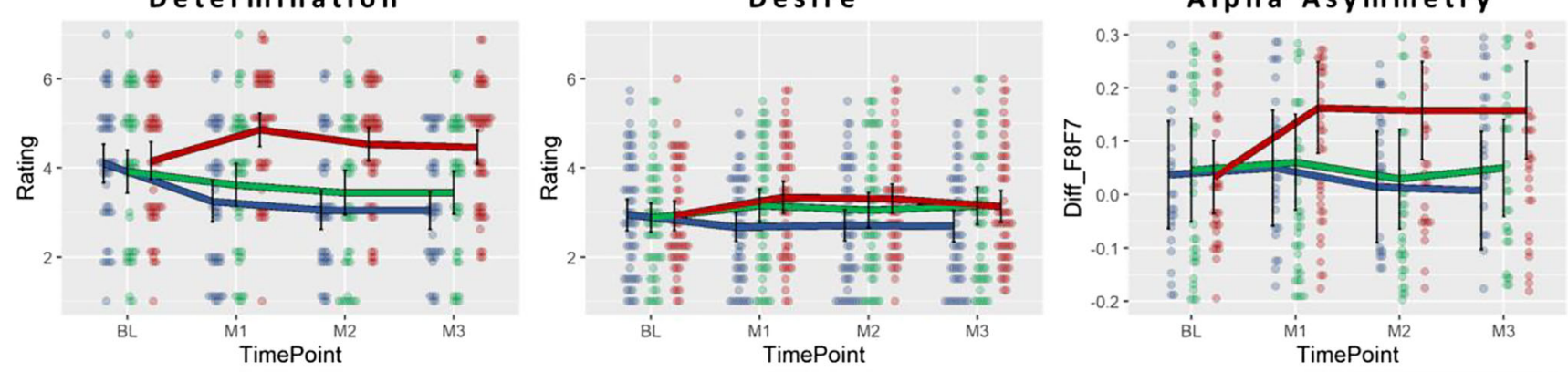

Neutral

Low Approach

High Approach

Fig. 2 Mean ratings of the manipulation check, including individual data points, error bars represent \pm 2 SEM. Subjective ratings and frontal alpha asymmetry are shown separately for the neutral, low approach positive,

Frontal alpha-asymmetry The ANOVA showed a significant effect of Time, $F(1.9,305)=3.62, p=0.029, \eta^{2}=$ 0.022 , as well as a significant interaction between Time and Mood, $F(3.9,305)=2.59, p=0.038, \eta^{2}=0.031$. Post-hoc tests showed that neither the low approach positive mood nor the neutral mood showed a change in frontal alpha asymmetry across the different measurement points compared with the baseline measurement (all $p \mathrm{~s} \geq 0.99$ ). By comparison, participants in high approach positive mood showed greater left relative to right frontal cortical activity after the first mood induction, as well as all subsequent repetitions compared with the baseline period ( $p$ s $\leq 0.013$; Figure 2). and high approach positive moods as a function of time, including the baseline measurement (BL) and three repetitions of the mood induction (M1-M3).

\section{Catch Trials}

For reward probability (cue), accuracy was very high, with an average of $94.9 \%(S D=7.05)$ of correct responses. The three mood conditions did not differ on this metric, $F(2,158)=0.11$, $p=0.89, \eta^{2}=0.001$. For the ratings of feedback's expectedness, the ANOVA showed significant main effects of feedback Expectancy, $F(1,158)=102.94, p<0.001, \eta^{2}=0.38$, and feedback Valence, $F(1,158)=69.13, p<0.001, \eta^{2}=0.30$. The interaction between Mood and Expectancy was also significant, $F(2,158)=5.31, p=0.006, \eta^{2}=0.039$. Expected feedback was rated to be more expected than unexpected feedback $(p<0.001)$, confirming the efficacy of the manipulation. 
Moreover, reward feedback was more expected than noreward feedback $(p<0.001)$, indicating an expectancy bias towards reward feedback (Figure 3). Although post-hoc tests were not significant, the interaction between Mood and Expectancy indicated that participants in high approach positive mood did expect unexpected feedback even less than the neutral group $(p=0.061)$. No other main effects or interactions were significant, $F_{\mathrm{S}} \leq 1.77, p \mathrm{~s} \geq 0.17, \eta^{2} \mathrm{~s} \leq 0.013$ Figure 3.

\section{EEG data}

RewP The ANOVA showed a significant main effect of feedback Valence, $F(1,158)=329, p \leq 0.001, \eta^{2}=0.67$, as well as a significant main effect of Expectancy, $F(1,158)=8.22, p=$ $0.005, \eta^{2}=0.049$. Reward feedback elicited a larger (more positive) RewP component compared to no-reward feedback $(p<0.001)$ and unexpected compared with expected feedback $(p<0.001)$. No other effects reached the level of significance, $F_{\mathrm{s}} \leq 1.35, p \geq .26, \eta^{2} \leq 0.017$ (Figure 4; Table 1). To assess the evidence in favor of the null hypothesis (i.e., the lack of mood effect on the RewP), we ran a JZS Bayes factor repeatedmeasurement ANOVA. As expected, the model including feedback Valence and Expectancy explained the data the best $(\mathrm{BF} 10=1.02 \mathrm{e}+56)$, i.e., four times better than any model, including Mood. The change from prior to posterior inclusion odds averaged across all candidate models, i.e., BFInclusion, showed clear support for the main effect of Valence (BFInclusion $=3.22 \mathrm{e}+15)$. Mild to anecdotal evidence was found against the main effect of Expectancy (BFInclusion = 0.54 ) and the interaction of both (BFInclusion $=0.23$ ). Importantly, the odds for any model including the factor Mood were very low (BFInclusion $=0.091-0.008$ ), indicating strong to very strong evidence for the null hypothesis, i.e., that mood did not influence the RewP. Similarly, when we only compared the two positive mood conditions, we found moderate to strong evidence for the null hypothesis, i.e., that motivational intensity did not influence the RewP (BFInclusion $=$ $0.239-0.002)$.
FM $\theta$ The ANOVA showed significant main effects of feedback Expectancy, $F(1,158)=17.6, p<0.001, \eta^{2}=0.099$, and feedback Valence, $F(1,158)=74.8, p<0.001, \eta^{2}=0.32$, as well as the interaction between them, $F(1,158)=5.27, p=$ $0.002, \eta^{2}=0.054$. Importantly the three-way interaction between feedback Expectancy, Valence and Mood was also significant, $F(2,158)=4.26, p=0.016, \eta^{2}=0.048$. All mood conditions showed a stronger FM $\theta$ activity in response to noreward compared with reward feedback (all $p$ s $\leq 0.022$ ). However, only participants in neutral mood showed more FM $\theta$ activity for unexpected reward compared to expected reward $(p=0.006)$. By comparison, neither low approach positive mood $(p=0.38)$ nor high approach positive mood $(p=0.17)$ actually showed increased FM $\theta$ activity for unexpected compared with expected feedback when this feedback was rewarding, while this was the case for no-reward feedback (neutral: $p=0.027$, low approach positive mood: $p=0.001$, high approach positive mood: $p=0.001$; Figure 5). No other main effects or interaction approached the level of significance, $F_{\mathrm{s}} \leq 2.17, p \mathrm{~s} \geq 0.12, \eta^{2} \mathrm{~s} \leq 0.027$. We also ran a JZS Bayes factor repeated measurement ANOVA to compare the two positive mood groups directly. As expected, the model, including the interaction of Valence and Expectancy, fit the data the best $(\mathrm{BF} 10=1.35 \mathrm{e}+14)$. The change from prior to posterior inclusion odds averaged across all candidate models, i.e., BFInclusion, showed clear support for the main effect of Valence $(\mathrm{BF} 1 \mathrm{nc} 1 \mathrm{usion}=1.72 \mathrm{e}+13)$ and Expectancy $(\mathrm{BF} 1 \mathrm{nc} 1 \mathrm{usion}=45.7)$, and their interaction $(\mathrm{BF} 1 \mathrm{nc} 1 \mathrm{usion}=$ 33.6). Mild to anecdotal evidence was found against any effect of Mood (BF1nclusion $=0.77-0.068$ ), indicating that motivational intensity did not influence FMS activity.

\section{Discussion}

In a previous EEG study (Paul \& Pourtois, 2017), we found specific changes during reward processing following the induction of positive mood. However, because positive mood and approach motivation can co-vary, it remained unclear

Feedback Expectedness

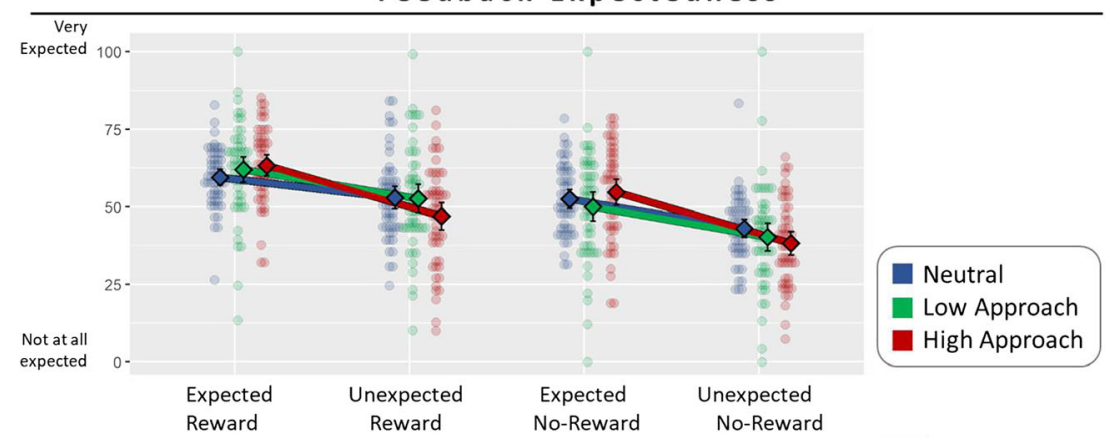

Fig. 3 Mean ratings of feedback expectedness, including individual data points for each feedback condition and mood. Rhombs are centered on the mean; error bars represent \pm 2 SEM. 


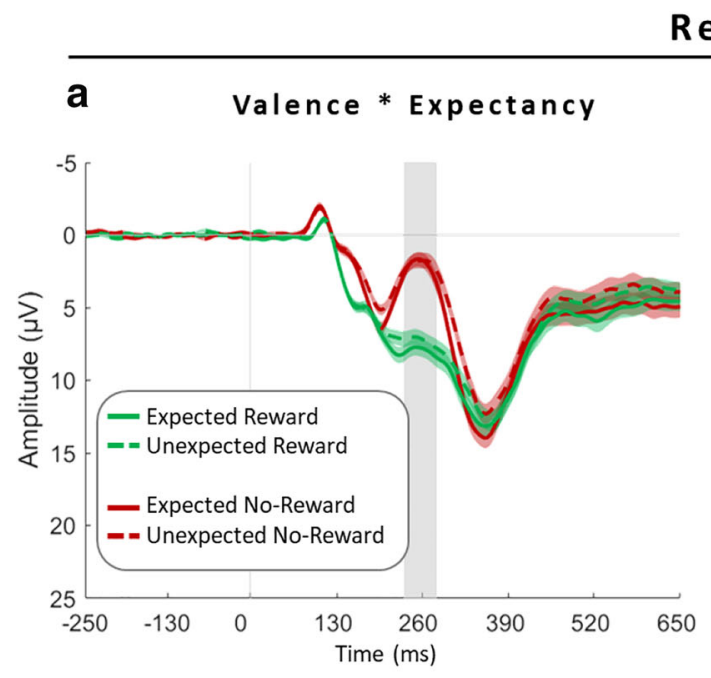

C

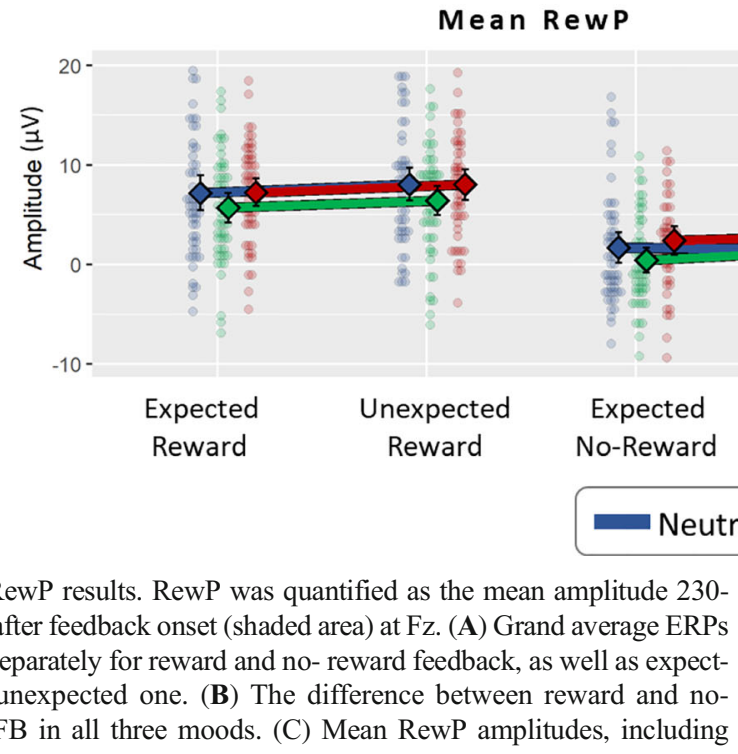

what eventually drove these changes. To disentangle effects of positive mood from approach motivation on reward processing, we combined a gambling task (Hajcak, Holroyd, Moser, \& Simons, 2005; Hajcak et al., 2007) with affective state manipulations, and measured reward processing at the EEG levels. Mood of participants was altered by means of a mindset manipulation combined with an imagery procedure to induce either neutral or positive mood. In addition, the positive mood induction was accompanied by either a low or high approach motivation induction. EEG results showed that under positive mood and irrespective of approach motivation intensity, FM $\theta$ activity did not differentiate if reward feedback was expected or not, while FM $\theta$ activity was clearly larger for unexpected compared with expected no-reward feedback. Because this effect was equally strong in both positive mood conditions (compared with a neutral mood control condition), and hence occurred irrespective of the approach motivation intensity, this result suggested that positive affect

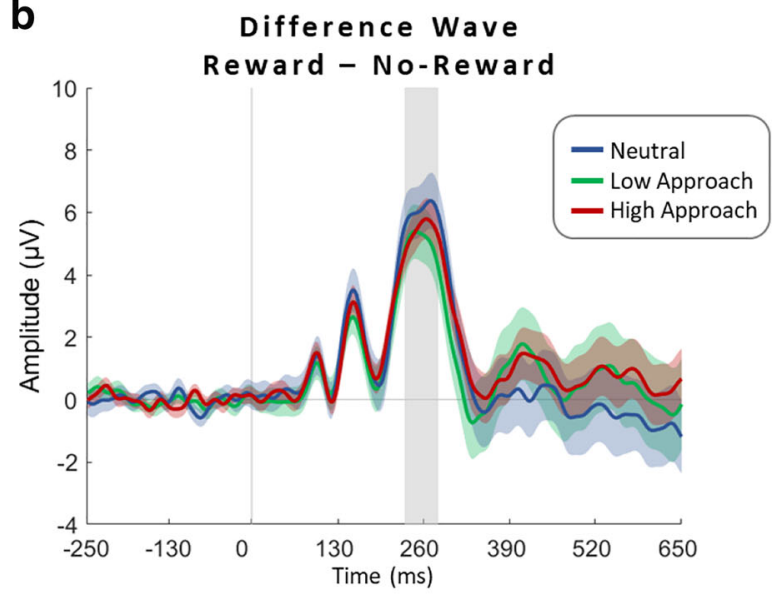

d

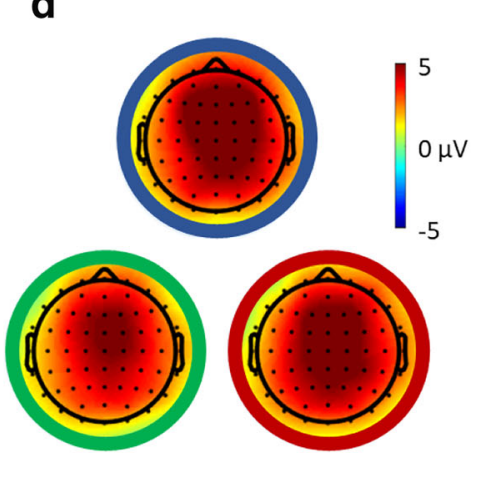

Unexpected

No-Reward

(n)

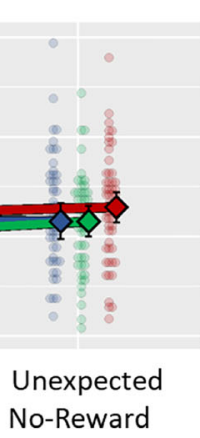

High Approach

individual data points for each feedback condition and mood. Rhombs are centered on the mean; error bars represent \pm 2 SEM. (D) Topographical maps (horizontal view) of the difference between reward and no-reward feedback for each mood condition separately. Colorful areas around the ERPs in (A) and (B) represent \pm SEM.

(but not approach motivation) likely changed reward expectation in a mood congruent way, thereby replicating and extending our previous results (Paul \& Pourtois, 2017). In comparison, mood did not change the RewP. Below, we discuss the possible implications of these new findings for neurobiological models of reward processing in the existing literature.

The mood induction procedure turned out to be successful as confirmed by both subjective ratings and frontal alpha asymmetry. By combining a mindset manipulation (E. Harmon-Jones et al., 2008) with an imagery procedure (Bakic et al., 2014; Paul \& Pourtois, 2017; Paul et al., 2019; Vanlessen et al., 2013), participants in the three mood groups differed from each other along both positive mood and approach motivation intensity. More specifically, participants in both positive mood conditions (irrespective of approach motivation intensity) reported feeling happier at the subjective level, compared to participants in neutral mood. However and importantly, only participants in positive high approach mood 
FMO Power (Fz)

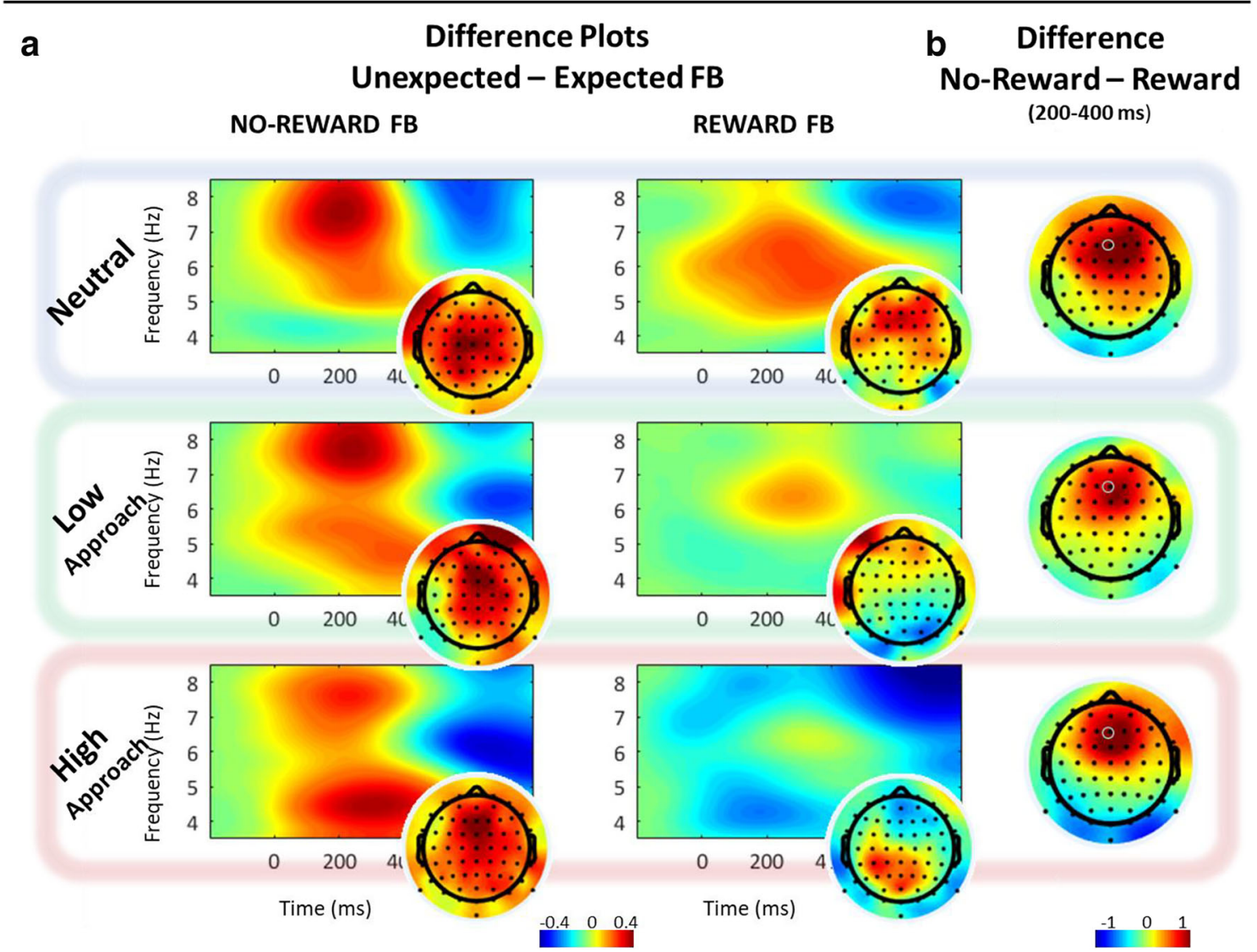

C

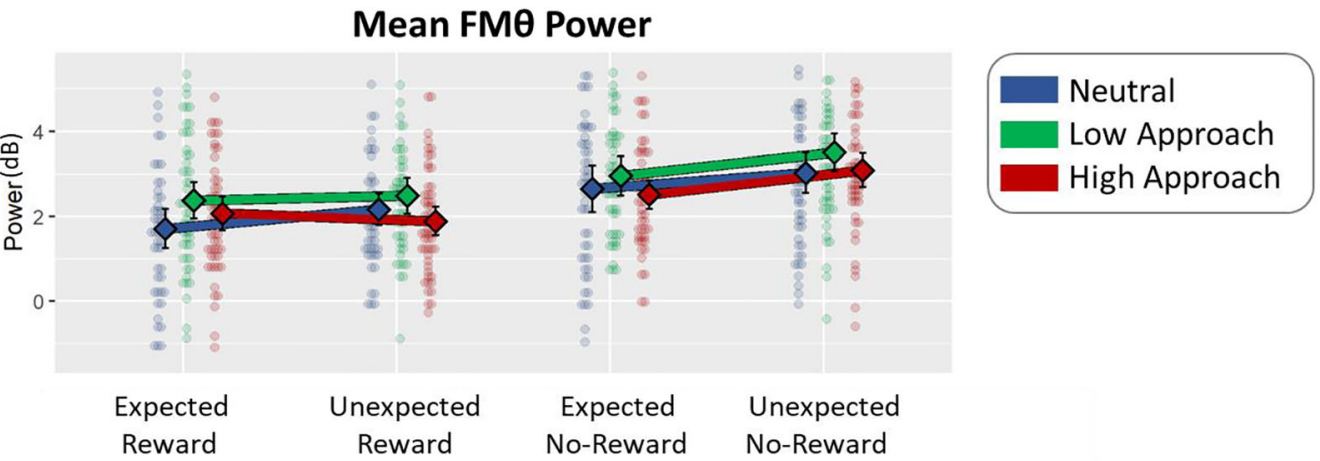

Fig. 5 FMS activity results. FMS activity was defined as the mean between 200-400 ms at electrode Fz. (A) Difference between unexpected and expected feedback, separately for reward and no-reward and each mood condition. (B) Topographical representation of the difference

reported feeling more determined (and less relaxed) than those included in the two other mood groups. Moreover, only these former participants showed higher left relative to right frontal activity after mood induction, corroborating the assumption that approach motivation was increased (Coan \& Allen, 2004; E. Harmon-Jones, Gable, \& Peterson, 2010; Smith et al., 2016). Therefore, we could compare reward processing when either positive mood or approach motivation was elicited, with the goal to assess whether they led to similar or dissociable effects. between reward and no-reward for each mood condition. (C) Mean FMS activity, including individual data points for each feedback condition and mood. Rhombs are centered on the mean; error bars represent \pm 2 SEM.

Replicating our previous results (Paul \& Pourtois, 2017), we found that FM $\theta$ activity in both positive mood conditions (irrespective of approach motivation intensity) did not differentiate if reward feedback was unexpected or not, while it clearly did differentiate if no-reward feedback was unexpected or not. Tentatively, this neurophysiological effect could translate an optimistic bias in these two mood groups characterized by enhanced positive mood (Eldar et al., 2016; Loewenstein \& Lerner, 2003; Wright \& Bower, 1992). Moreover, when brought together with our previous EEG results (Paul \& 
Pourtois, 2017), these new findings confirm that positive mood, but not approach motivation, was likely the underlying factor responsible for this specific change during reward processing. Positive mood can alter the processing of reward (positive) prediction error signals, which are instrumental to (de) code the degree of mismatch between the actual and expected outcome (Holroyd \& Coles, 2002; Sambrook \& Goslin, 2015; Schultz, 2015; Schultz, Dayan, \& Montague, 1997; Ullsperger, Fischer, Nigbur, \& Endrass, 2014b; Walsh \& Anderson, 2012). By comparison, approach motivation did not appear to produce distinctive changes in FM $\theta$ activity in our study. More generally, FM $\theta$ activity is thought to reflect the need for cognitive control (Cavanagh, Eisenberg, Guitart-Masip, Huys, \& Frank, 2013; Cavanagh \& Frank, 2014; Cavanagh, Zambrano-Vazquez, \& Allen, 2012b; Swart et al., 2018). Accordingly, it is conceivable that positive mood could loosen cognitive control in a context specific manner (i.e., when reward is expected) rather than altering reward processing per se.

This interpretation is also supported indirectly by the lack of systematic modulation of the RewP as a function of positive mood or approach motivation in our study. Although the amplitude of the RewP was clearly larger for reward compared to no-reward feedback (Holroyd et al., 2008; Sambrook \& Goslin, 2015; Ullsperger, Danielmeier, \& Jocham, 2014a), this rewardsensitivity effect was similar for the three mood groups (as confirmed by a Bayesian analysis). Based on our previous study (Paul \& Pourtois, 2017) and previous research on approach motivation and reward sensitivity (Angus et al., 2015; Bress \& Hajcak, 2013; Cooper et al., 2014; Threadgill \& Gable, 2016, 2018), we nonetheless expected that an increase in approach motivation and/or positive affect would lead to a larger RewP component. Tentatively, this discrepancy between these previous findings and the current results for the RewP could be explained by some methodological factors, including the way approach motivation was elicited, and hence its relation to reward processing. In these previous studies, approach motivation was usually contingent and task relevant, comparing monetary reward to conditions without this incentive (Threadgill \& Gable, 2016, 2018), or comparing conditions varying in reward magnitude (Meadows, Gable, Lohse, \& Miller, 2016; Paul et al., 2019). In comparison, in the current study, we capitalized on a mood induction procedure that was orthogonal to the gambling task and not coupled to reward. Thus, it may be the case that approach motivation could increase the RewP when it is directly task- and goal-relevant, but less able to do so when it is orthogonal to the (gambling) task, and hence, not immediately goal relevant. However, when being task-irrelevant, approach motivation can nonetheless lead to some behavioral effects, including preference judgements for in decision making (E. Harmon-Jones \& Harmon-Jones, 2002; E. Harmon- Jones et al., 2008), aggressive inclinations (E. Harmon-Jones \& Peterson, 2008), and perceived control (Gollwitzer \& Kinney, 1989). Accordingly, future studies are needed to determine the necessary conditions for a systematic modulation of the RewP, besides subjective ratings, as a function of approach motivation.

Because of this apparent difference between the RewP and FM $\theta$ activity in our study, these new results also add to a growing literature suggesting that these two neurophysiological components can capture dissociable effects during reward processing and are complementing one another, even though they probably share a common neurobiological ground (Cavanagh, Frank, Klein, \& Allen, 2010; Cavanagh, Zambrano-Vazquez, et al., 2012b; Cohen, Elger, \& Ranganath, 2007). Whereas the RewP is mostly linked to the processing of signed reward prediction errors (i.e., when the outcome is better than expected), FM $\theta$ activity is usually larger for unsigned reward prediction errors (i.e., when the outcome is either worse or better than expected; Hajihosseini \& Holroyd, 2013; Osinsky, Seeger, Mussel, \& Hewig, 2016). Using this framework, our results therefore suggest that positive mood could decrease the expectancy of reward selectively (FM $\theta$ activity), while leaving reward sensitivity (RewP) unaffected. Importantly, we could show here that positive mood, rather than approach motivation, accounted for this change during reward processing.

Last, a caveat warrants comment. We found that the subjective ratings for feedback's expectedness did not perfectly align with FM $\theta$ results. We believe that this dissociation likely resulted from the way these ratings were administered. Because they were provided after but not before feedback processing, it is likely that they mostly captured objective reward probability rather than subjective expectancy (Windschitl, Smith, Rose, \& Krizan, 2010). Feedback's expectedness was not rated before feedback delivery, as we did not want to break the normal trial sequence (choosing a door followed by evaluative feedback). In this context, complex updating and integration processes between reward expectancy and reward consumption likely took place, making these ratings imperfect evaluations of reward expectancy. Accordingly, the question remains whether purer measures of reward expectancy at the subjective level might better align with FM $\theta$ activity than in the present case.

To conclude, the present study informs about modulatory effects created by positive mood and approach motivation on reward processing. Results showed that the former but not the latter variable influenced reward processing, by altering reward expectancy selectively, with an effect visible at the FM $\theta$ level. In comparison, reward sensitivity, as measured by the RewP, was not influenced by positive mood or approach motivation. We interpret these results in terms of an optimistic bias unlocked by positive mood during gambling, whereby unexpected reward is no longer processed as surprising in this specific mood state. More generally, these findings emphasize that reward-related brain processes are flexible and shaped by the current affective and motivational state of the participant. 
Open Practices Statement The data, materials and code for all experiments are available at https://osf.io/kc42t/. The experiment was not preregistered.

\section{References}

Angus, D. J., Kemkes, K., Schutter, D. J. L. G., \& Harmon-Jones, E. (2015). Anger is associated with reward-related electrocortical activity: Evidence from the reward positivity. Psychophysiology, 52(10), 1271-1280. doi:https://doi.org/10.1111/psyp.12460

Bakic, J., Jepma, M., De Raedt, R., \& Pourtois, G. (2014). Effects of positive mood on probabilistic learning: Behavioral and electrophysiological correlates. Biological Psychology, 103, 223-232. doi:https://doi.org/10.1016/j.biopsycho.2014.09.012

Bress, J. N., \& Hajcak, G. (2013). Self-report and behavioral measures of reward sensitivity predict the feedback negativity. Psychophysiology, 50(7), 610-616. doi:https://doi.org/10.1111/ psyp. 12053

Carver, C. S., \& Harmon-Jones, E. (2009). Anger is an approach-related affect: Evidence and implications. Psychological Bulletin, 135(2), 183-204. doi:https://doi.org/10.1037/a0013965

Carver, C. S., \& White, T. L. (1994). Behavioral inhibition, behavioral activation, and affective responses to impending reward and punishment: The BIS/BAS Scales. Journal of Personality and Social Psychology. doi:https://doi.org/10.1037/0022-3514.67.2.319

Cavanagh, J. F., Eisenberg, I., Guitart-Masip, M., Huys, Q., \& Frank, M. J. (2013). Frontal Theta Overrides Pavlovian Learning Biases. Journal of Neuroscience, 33(19), 8541-8548. doi:https://doi.org/ 10.1523/JNEUROSCI.5754-12.2013

Cavanagh, J. F., Figueroa, C. M., Cohen, M. X., \& Frank, M. J. (2012a). Frontal Theta Reflects Uncertainty and Unexpectedness during Exploration and Exploitation. Cerebral Cortex, 22(11), 25752586. doi:https://doi.org/10.1093/cercor/bhr332

Cavanagh, J. F., \& Frank, M. J. (2014). Frontal theta as a mechanism for cognitive control. Trends in Cognitive Sciences, 18(8), 414-421. doi:https://doi.org/10.1016/j.tics.2014.04.012

Cavanagh, J. F., Frank, M. J., Klein, T. J., \& Allen, J. J. B. (2010). Frontal theta links prediction errors to behavioral adaptation in reinforcement learning. NeuroImage, 49(4), 3198-3209. doi:https://doi.org/ 10.1016/j.neuroimage.2009.11.080

Cavanagh, J. F., Napolitano, A., Wu, C., \& Mueen, A. (2017). The Patient Repository for EEG Data + Computational Tools (PRED+CT). Frontiers in Neuroinformatics, 11(67), 1-9. doi:https://doi.org/10. 3389/fninf.2017.00067

Cavanagh, J. F., Zambrano-Vazquez, L., \& Allen, J. J. B. (2012b). Theta lingua franca: A common mid- frontal substrate for action monitoring processes. Psychophysiology, 49(2), 220-238. doi:https://doi. org/10.1111/j.1469-8986.2011.01293.x

Coan, J. A., \& Allen, J. J. . (2004). Frontal EEG asymmetry as a moderator and mediator of emotion. Biological Psychology, 67(1-2), 7 50. doi:https://doi.org/10.1016/j.biopsycho.2004.03.002

Cohen, M. X., Elger, C. E., \& Ranganath, C. (2007). Reward expectation modulates feedback-related negativity and EEG spectra. NeuroImage, 35(2), 968-978. doi:https://doi.org/10.1016/j. neuroimage.2006.11.056

Cook, I. A., O'Hara, R., Uijtdehaage, S. H. J., Mandelkern, M., \& Leuchter, A. F. (1998). Assessing the accuracy of topographic EEG mapping for determining local brain function. Electroencephalography and Clinical Neurophysiology, 107(6), 408-414. doi:https://doi.org/10.1016/S0013-4694(98)00092-3

Cooper, A. J., Duke, Ã., Pickering, A. D., \& Smillie, L. D. (2014). Individual differences in reward prediction error: contrasting relations between feedback-related negativity and trait measures of reward sensitivity, impulsivity and extraversion. Frontiers in Human Neuroscience, 8, 248. doi:https://doi.org/10.3389/fnhum. 2014.00248

Delorme, A., \& Makeig, S. (2004). EEGLAB: an open source toolbox for analysis of single-trial EEG dynamics including independent component analysis. Journal of Neuroscience Methods, 134(1), 9-21. doi:https://doi.org/10.1016/j.jneumeth.2003.10.009

Diener, E., Emmons, R. A., Larsen, R. J., \& Griffin, S. (1985). The satisfaction with life scale. Journal of Personality Assessment, 49(1), 71-75. doi:https://doi.org/10.1207/s15327752jpa4901_13

Eldar, E., Rutledge, R. B., Dolan, R. J., \& Niv, Y. (2016). Mood as Representation of Momentum. Trends in Cognitive Sciences, 20(1), 15-24. doi:https://doi.org/10.1016/j.tics.2015.07.010

Faul, F., Erdfelder, E., Lang, A.-G., \& Buchner, A. (2007). G*Power 3: A flexible statistical power analysis program for the social, behavioral, and biomedical sciences. Behavior Research Methods, 39(2), 175 191. doi:https://doi.org/10.3758/BF03193146

Fell, J., Dietl, T., Grunwald, T., Kurthen, M., Klaver, P., Trautner, P., Fernández, G. (2004). Neural Bases of Cognitive ERPs: More than Phase Reset. Journal of Cognitive Neuroscience, 16(9), 1595-1604. doi:https://doi.org/10.1162/0898929042568514

Fiorillo, C. D., Tobler, P. N., \& Schultz, W. (2003). Discrete Coding of Reward Probability and Uncertainty by Dopamine Neurons. Science, 299(5614), 1898-1902. doi:https://doi.org/10.1126/ science. 1077349

Gable, P., \& Harmon-Jones, E. (2010). The motivational dimensional model of affect: implications for breadth of attention, memory, and cognitive categorisation. Cognition \& Emotion, 24(2), 322-337. doi:https://doi.org/10.1080/02699930903378305

Gheza, D., De Raedt, R., Baeken, C., \& Pourtois, G. (2018a). Integration of reward with cost anticipation during performance monitoring revealed by ERPs and EEG spectral perturbations. NeuroImage, 173, 153-164. doi:https://doi.org/10.1016/j.neuroimage.2018.02. 049

Gheza, D., Paul, K., \& Pourtois, G. (2018b). Dissociable effects of reward and expectancy during evaluative feedback processing revealed by topographic ERP mapping analysis. International Journal of Psychophysiology, 132, 213-225. doi:https://doi.org/10.1016/j. ijpsycho.2017.11.013

Gollwitzer, P. M., \& Kinney, R. F. (1989). Effects of deliberative and implemental mind-sets on illusion of control. Journal of Personality and Social Psychology, 56(4), 531-542. doi:https:// doi.org/10.1037/0022-3514.56.4.531

Hajcak, G., Holroyd, C. B., Moser, J. S., \& Simons, R. F. (2005). Brain potentials associated with expected and unexpected good and bad outcomes. Psychophysiology, 42(2), 161-170. doi:https://doi.org/ 10.1111/j.1469-8986.2005.00278.x

Hajcak, G., Moser, J. S., Holroyd, C. B., \& Simons, R. F. (2007). It's worse than you thought: The feedback negativity and violations of reward prediction in gambling tasks. Psychophysiology, 44(6), 905912. doi:https://doi.org/10.1111/j.1469-8986.2007.00567.x

Hajihosseini, A., \& Holroyd, C. B. (2013). Frontal midline theta and N200 amplitude reflect complementary information about expectancy and outcome evaluation. Psychophysiology, 50(6), 550-562. doi: https://doi.org/10.1111/psyp.12040

Harmon-Jones, C., Bastian, B., \& Harmon-Jones, E. (2016). The Discrete Emotions Questionnaire: A New Tool for Measuring State SelfReported Emotions. PLOS ONE, 11(8), e0159915. doi:https://doi. org/10.1371/journal.pone.0159915

Harmon-Jones, E. (2007). Trait anger predicts relative left frontal cortical activation to anger-inducing stimuli. International Journal of Psychophysiology, 66(2), 154-160. doi:https://doi.org/10.1016/j. ijpsycho.2007.03.020

Harmon-Jones, E., \& Gable, P. A. (2018). On the role of asymmetric frontal cortical activity in approach and withdrawal motivation: An 
updated review of the evidence. Psychophysiology, 55(1), e12879. doi:https://doi.org/10.1111/psyp.12879

Harmon-Jones, E., Gable, P. a., \& Peterson, C. K. (2010). The role of asymmetric frontal cortical activity in emotion-related phenomena: a review and update. Biological Psychology, 84(3), 451-462. doi: https://doi.org/10.1016/j.biopsycho.2009.08.010

Harmon-Jones, E., Gable, P. A., \& Price, T. F. (2013a). Does negative affect always narrow and positive affect always broaden the mind? considering the influence of motivational intensity on cognitive scope. Current Directions in Psychological Science, 22(4), 301307. doi:https://doi.org/10.1177/0963721413481353

Harmon-Jones, E., \& Harmon-Jones, C. (2002). Testing the action-based model of cognitive dissonance: the effect of action orientation on postdecisional attitudes. Personality and Social Psychology Bulletin, 28(6), 711-723. doi:https://doi.org/10.1177/ 0146167202289001

Harmon-Jones, E., Harmon-Jones, C., Abramson, L., \& Peterson, C. K. (2009). PANAS positive activation is associated with anger. Emotion, 9(2), 183-196. doi:https://doi.org/10.1037/a0014959

Harmon-Jones, E., Harmon-Jones, C., Fearn, M., Sigelman, J. D., \& Johnson, P. (2008). Left frontal cortical activation and spreading of alternatives: tests of the action-based model of dissonance. Journal of Personality and Social Psychology, 94(1), 1-15. doi:https://doi. org/10.1037/0022-3514.94.1.1

Harmon-Jones, E., Harmon-Jones, C., \& Price, T. F. (2013b). What is approach motivation? Emotion Review, 5(3), 291-295. doi:https:// doi.org/10.1177/1754073913477509

Harmon-Jones, E., \& Peterson, C. K. (2008). Effect of trait and state approach motivation on aggressive inclinations. Journal of Research in Personality, 42(5), 1381-1385. doi:https://doi.org/10. 1016/j.jrp.2008.05.001

Hauser, T. U., Iannaccone, R., Stämpfli, P., Drechsler, R., Brandeis, D., Walitza, S., \& Brem, S. (2014). The feedback-related negativity (FRN) revisited: New insights into the localization, meaning and network organization. NeuroImage, 84, 159-168. doi:https://doi. org/10.1016/j.neuroimage.2013.08.028

Holmes, E. A., Coughtrey, A. E., \& Connor, A. (2008). Looking at or through rose-tinted glasses? Imagery perspective and positive mood. Emotion, 8(6), 875-879. doi:https://doi.org/10.1037/a0013617

Holmes, E. A., Mathews, A., Dalgleish, T., \& Mackintosh, B. (2006). Positive Interpretation Training: Effects of Mental Imagery Versus Verbal Training on Positive Mood. Behavior Therapy, 37(3), 237247. doi:https://doi.org/10.1016/j.beth.2006.02.002

Holroyd, C. B., \& Coles, M. G. H. (2002). The neural basis of human error processing: Reinforcement learning, dopamine, and the errorrelated negativity. Psychological Review, 109(4), 679-709. doi: https://doi.org/10.1037/0033-295X.109.4.679

Holroyd, C. B., Pakzad-Vaezi, K. L., \& Krigolson, O. E. (2008). The feedback correct-related positivity: Sensitivity of the event-related brain potential to unexpected positive feedback. Psychophysiology, 45(5), 688-697. doi:https://doi.org/10.1111/j.1469-8986.2008. 00668.x

Loewenstein, G., \& Lerner, J. S. (2003). The role of affect in decision making. In R. J. Davidson, K. R. Scherer, \& H. H. Goldsmith (Eds.), Handbook of affective science (pp. 619-642). New York, NY, US: Oxford University Press

Makeig, S., Westerfield, M., Jung, T.-P., Enghoff, S., Townsend, J., Courchesne, E., \& Sejnowski, T. J. (2002). Dynamic brain sources of visual evoked responses. Science, 295(5555), 690-694. doi: https://doi.org/10.1126/science.1066168

Mas-Herrero, E., \& Marco-Pallarés, J. (2014). Frontal theta oscillatory activity is a common mechanism for the computation of unexpected outcomes and learning rate. Journal of Cognitive Neuroscience, 26(3), 447-458. doi:https://doi.org/10.1162/jocn_a_00516

Mayer, J. D., Gaschke, Y. N., Braverman, D. L., \& Evans, T. W. (1992). Mood-congruent judgment is a general effect. Journal of
Personality and Social Psychology, 63(1), 119-132. doi:https:// doi.org/10.1037/0022-3514.63.1.119

Meadows, C. C., Gable, P. A., Lohse, K. R., \& Miller, M. W. (2016). The effects of reward magnitude on reward processing: An averaged and single trial event-related potential study. Biological Psychology, 118, 154-160. doi:https://doi.org/10.1016/j.biopsycho.2016.06.002

Moser, J. S., Hajcak, G., \& Simons, R. F. (2005). The effects of fear on performance monitoring and attentional allocation. Psychophysiology, 42(3), 261-268. doi:https://doi.org/10.1111/j. 1469-8986.2005.00290.x

Nolan, H., Whelan, R., \& Reilly, R. B. (2010). FASTER: Fully Automated Statistical Thresholding for EEG artifact Rejection. Journal of Neuroscience Methods, 192(1), 152-162. doi:https:// doi.org/10.1016/j.jneumeth.2010.07.015

Nusslock, R., \& Alloy, L. B. (2017). Reward processing and moodrelated symptoms: An RDoC and translational neuroscience perspective. Journal of Affective Disorders, 216(6), 3-16. doi:https:// doi.org/10.1016/j.jad.2017.02.001

Osinsky, R., Seeger, J., Mussel, P., \& Hewig, J. (2016). Face-induced expectancies influence neural mechanisms of performance monitoring. Cognitive, Affective, \& Behavioral Neuroscience, 16(2), 261275. doi:https://doi.org/10.3758/s13415-015-0387-y

Paul, K., \& Pourtois, G. (2017). Mood congruent tuning of reward expectation in positive mood: evidence from FRN and theta modulations. Social Cognitive and Affective Neuroscience, 12(5), 765-774. doi:https://doi.org/10.1093/scan/nsx010

Paul, K., Vassena, E., Severo, M. C., \& Pourtois, G. (2019). Dissociable effects of reward magnitude on fronto-medial theta and FRN during performance monitoring. Psychophysiology, 17(1), 106-123. doi: https://doi.org/10.1111/psyp.13481

Proudfit, G. H. (2015). The reward positivity: From basic research on reward to a biomarker for depression. Psychophysiology, 52(4), 449-459. doi:https://doi.org/10.1111/psyp.12370

Sambrook, T. D., \& Goslin, J. (2015). A neural reward prediction error revealed by a meta-analysis of ERPs using great grand averages. Psychological Bulletin, 141(1), 213-235. doi:https://doi.org/10. 1037/bul0000006

Schultz, W. (2015). Neuronal Reward and Decision Signals: From Theories to Data. Physiological Reviews, 95(3), 853-951. doi: https://doi.org/10.1152/physrev.00023.2014

Schultz, W., Dayan, P., \& Montague, P. R. (1997). A Neural Substrate of Prediction and Reward. Science, 275(5306), 1593-1599. doi:https:// doi.org/10.1126/science.275.5306.1593

Sharot, T., Korn, C. W., \& Dolan, R. J. (2011). How unrealistic optimism is maintained in the face of reality. Nature Neuroscience, 14(11), 1475-1479. doi:https://doi.org/10.1038/nn.2949

Shiota, M. N., Neufeld, S. L., Danvers, A. F., Osborne, E. A., Sng, O., \& Yee, C. I. (2014). Positive Emotion Differentiation: A Functional Approach. Social and Personality Psychology Compass, 8(3), 104117. doi:https://doi.org/10.1111/spc3.12092

Smillie, L. D., Cooper, A. J., \& Pickering, A. D. (2011). Individual differences in reward-prediction- error: extraversion and feedbackrelated negativity. Social Cognitive and Affective Neuroscience, 6(5), 646-652. doi:https://doi.org/10.1093/scan/nsq078

Smith, E. E., Reznik, S. J., Stewart, J. L., \& Allen, J. J. B. (2016). Assessing and Conceptualizing Frontal EEG Asymmetry: An Updated Primer on Recording, Processing, Analyzing, and Interpreting Frontal Alpha Asymmetry. International Journal of Psychophysiology, 111, 98-114. doi:https://doi.org/10.1017/ CBO9781107415324.004

Sutton, R. S., \& Barto, A. G. (1998). Reinforcement Learning: An Introduction. IEEE Transactions on Neural Networks, 9(5), 1054. doi:https://doi.org/10.1109/TNN.1998.712192

Swart, J. C., Frank, M. J., Määttä, J. I., Jensen, O., Cools, R., \& den Ouden, H. E. M. (2018). Frontal network dynamics reflect neurocomputational mechanisms for reducing maladaptive biases 
in motivated action. PLOS Biology, 16(10), e2005979. doi:https:// doi.org/10.1371/journal.pbio.2005979

Threadgill, A. H., \& Gable, P. A. (2016). Approach-motivated pre-goal states enhance the reward positivity. Psychophysiology, 53(5), 733738. doi:https://doi.org/10.1111/psyp.12611

Threadgill, A. H., \& Gable, P. A. (2018). The sweetness of successful goal pursuit: Approach-motivated pregoal states enhance the reward positivity during goal pursuit. International Journal of Psychophysiology, 132(11), 277-286. doi:https://doi.org/10.1016/j. ijpsycho.2017.12.010

Tsypes, A., Angus, D. J., Martin, S., Kemkes, K., \& Harmon-Jones, E. (2019). Trait anger and the reward positivity. Personality and Individual Differences, 144(February), 24-30. doi:https://doi.org/ 10.1016/j.paid.2019.02.030

Ullsperger, M., Danielmeier, C., \& Jocham, G. (2014a). Neurophysiology of Performance Monitoring and Adaptive Behavior. Physiological Reviews, 94(1), 35-79. doi:https://doi.org/10.1152/physrev.00041. 2012

Ullsperger, M., Fischer, A. G., Nigbur, R., \& Endrass, T. (2014b). Neural mechanisms and temporal dynamics of performance monitoring. Trends in Cognitive Sciences, 18(5), 259-267. doi:https://doi.org/ 10.1016/j.tics.2014.02.009

Umemoto, A., \& Holroyd, C. B. (2017). Neural mechanisms of reward processing associated with depression-related personality traits.
Clinical Neurophysiology, 128(7), 1184-1196. doi:https://doi.org/ 10.1016/j.clinph.2017.03.049

Vanlessen, N., Rossi, V., De Raedt, R., \& Pourtois, G. (2013). Positive emotion broadens attention focus through decreased positionspecific spatial encoding in early visual cortex: Evidence from ERPs. Cognitive, Affective, \& Behavioral Neuroscience, 13(1), 60-79. doi:https://doi.org/10.3758/s13415-012-0130-x

Walsh, M. M., \& Anderson, J. R. (2012). Learning from experience: Event-related potential correlates of reward processing, neural adaptation, and behavioral choice. Neuroscience \& Biobehavioral Reviews, 36(8), 1870-1884. doi:https://doi.org/10.1016/j. neubiorev.2012.05.008

Windschitl, P. D., Smith, A. R., Rose, J. P., \& Krizan, Z. (2010). The desirability bias in predictions: Going optimistic without leaving realism. Organizational Behavior and Human Decision Processes, 111(1), 33-47. doi:https://doi.org/10.1016/j.obhdp.2009.08.003

Wright, W. F., \& Bower, G. H. (1992). Mood effects on subjective probability assessment. Organizational Behavior and Human Decision Processes, 52(2), 276-291. doi:https://doi.org/10.1016/07495978(92)90039-A

Publisher's note Springer Nature remains neutral with regard to jurisdictional claims in published maps and institutional affiliations. 